\title{
Improving Robotic Machining Accuracy through Experimental Error Investigation and Modular Compensation
}

\author{
Ulrich Schneider $^{\mathrm{a}^{*}}$, Manuel Drust ${ }^{\mathrm{a}}$, Matteo Ansaloni ${ }^{\mathrm{b}}$, Christian Lehmann $^{\mathrm{c}}$, \\ Marcello Pellicciari $^{\mathrm{b}}$, Francesco Leali ${ }^{\mathrm{b}}$, Jan Willem Gunnink ${ }^{\mathrm{d}}$, Alexander Verl ${ }^{\mathrm{a}}$ \\ ${ }^{a}$ Department of Robot and Assistive Systems, Fraunhofer Institute for Manufacturing \\ Engineering and Automation (IPA), Nobelstr. 12, 70565 Stuttgart, Germany \\ ${ }^{b}$ DIEF Engineering Department Enzo Ferrari, University of Modena and Reggio \\ Emilia, Via Vignolese 905/B, 41125 Modena, Italy \\ ${ }^{c}$ Chair of Automation Technology, Brandenburg University of Technology, Siemens- \\ Halske-Ring 14, 03046 Cottbus, Germany \\ ${ }^{d}$ Delcam PLC, Small Heath Business Park, Birmingham, B10 OHJ, UK \\ *Corresponding author: \\ Tel.: +497119701276 \\ Fax: +49 7119701008 \\ Email: ulrich.schneider@ipa.fraunhofer.de
}

\begin{abstract}
Machining using industrial robots is currently limited to applications with low geometrical accuracies and soft materials. This paper analyzes the sources of errors in robotic machining and characterizes them in amplitude and frequency. Experiments under different conditions represent a typical set of industrial applications and allow a qualified evaluation. Based on this analysis a modular approach is proposed to overcome these obstacles, applied both during program generation (offline) and execution (online). Predictive offline compensation of machining errors is achieved by means of an innovative programming system, based on kinematic and dynamic robot models. Real-time adaptive machining error compensation is also provided by sensing the real robot positions with an innovative tracking system and corrective feedback to both the robot and an additional high dynamic compensation mechanism on piezoactuator basis.
\end{abstract}

Keywords: robotic machining, robot dynamics, robot modelling, error compensation, optical tracking 


\section{Introduction}

Modern manufacturing industry requires production systems able to increase flexibility, to improve changeability and provide a high level of customization. In particular, reconfigurable manufacturing systems are a paradigm for production systems capable to deal with quick changes in product features, without compromising part quality, process reliability and life cycle costs [1]. Industrial robots are central to this paradigm. Nevertheless, industrial robots are traditionally used mainly for handling applications: according to the International Federation of Robotics (IFR) $72.7 \%$ of all industrial robots are used for handling and welding [2]. In fact, traditional industrial robots with six rotational axes enable high dexterity for complex manipulation tasks on a large work space. Only $2.0 \%$ of industrial robots are used for processes such as cutting, milling or grinding.

This is due to their larger set of error sources compared to machine tools: Industrial robots at state of the art perform only a limited set of machining operations [3]. In particular, robot machining is currently used for parts characterized by low accuracy and processes characterized by low contact forces such as polishing, deburring and deflashing. Despite this, there is still an increasing interest in using industrial robots for the described processes and according to the IFR, the usage of industrial robots for mechanical contact processes such as deburring, grinding and milling has increased by $41 \%$ from 2011 to 2012 [2]. In such scenario, despite their poor structural stiffness, industrial robots offer such a dexterity and cost to be competitive with a traditional 3 or 5 axis machine tool. As soon as higher precision is needed, robots are replaced by traditional machine tools with three linear axes and eventually two rotational axes, that are especially designed for maximum accuracy and are optimized for the machining process by providing high stiffness, improved assembly and calibration.

While industrial robots offer lower costs than a conventional machine tool, an exceptional flexibility and a big working area, more and more applications are identified in which industrial robots can perform machining operations [4]. Therefore, a much larger set of applications could be addressed by robots if the accuracy could be increased. This paper investigates the source of errors in robot machining and presents a modular approach for error compensation in order to improve the accuracy of industrial robots in machining operation. 
This paper is organized as follows. Section 1 describes the relevance of robot machining and the impact of the achieved accuracy. A survey on sources of errors is given in Section 2. Section 3 gives a detailed analysis of the characteristics of influences and provides dependencies. An overview on innovative methods for error compensation in Section 4 is followed by an outlook on demonstration presented in Section 5. The paper finishes with a discussion and conclusions of the presented analysis and methods in Section 6.

\section{Survey on Sources of Errors in Robot Machining}

Among the different performances related to the robot itself, precision is often used to describe its capabilities, and is further divided in: repeatability, accuracy and resolution. Repeatability and accuracy estimate the closeness between a set of attained positions and orientations of the TCP, when repeating the robot motions into the same commanded pose and their nominal values [5]. Resolution encompasses also programming resolution. Since industrial robots were designed to execute repeatable operations, their accuracy is lower than their repeatability. Typical accuracies of industrial manipulators are in the range of $\pm 1 \mathrm{~mm}$ [6], [7], but values of $0.3 \mathrm{~mm}$ can be reached with accurate compensation [8]. Repeatability ranges in $0.1-0.03 \mathrm{~mm}$ [9].

In order to obtain a clarification of the sources, a first distinction can be carried out among sources of errors in the robot itself (its mechanical structure, foundation and control system) or robot dependent, sources external to the robot (cell and auxiliary devices) and process (or task) dependent sources.

\subsection{Environment Dependent Errors}

The real accuracy of a robot depends strongly on the full chain of components between the tool on the TCP and the floor. Starting from the environment the structure of the building has an impact on the behaviour of the robot. The presence of a basement changes the transmission from the environment on the robot. Especially, when measuring in the range of $\mu \mathrm{m}$, those effects cannot be neglected. In Fig. 1 a typical situation for a production facility environment is considered, disturbances arising from a pallet truck and passing people are applied. The signals are the relative movement between a 1D-Lasersensor LK-G87 from Keyence, with an accuracy of $1 \mu \mathrm{m}$, and the robot which are both attached on the 14 tons machine bed (compare Fig. 5). An FFT of 

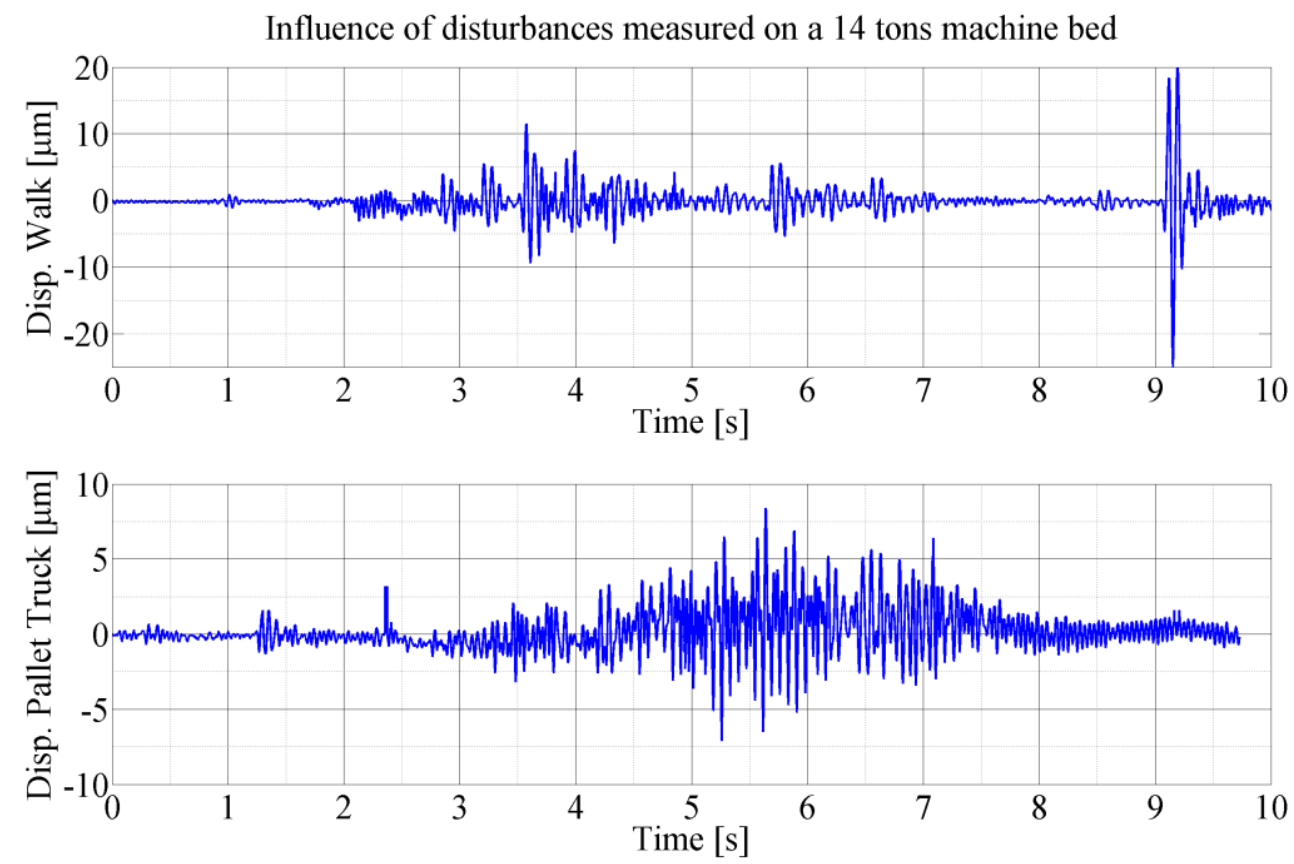

Fig. 1 Influence of disturbances measured on a 14 tons machine bed: Excitation by pallet truck and walking people

the signals reveals the main resonances to be similar to the resonances of the robot. It can be concluded that the measured signal is a real movement of the robot due to disturbances from the environment.

The chain of transmission of disturbances continues with the material of the floor and the fixture of the robot to the floor. Due to the big lever from the base to the tool small deformations in the base lead to big deviations on the tool. Moreover, an influence which must not be neglected is temperature. Different materials with different coefficients are used within an industrial robot which leads to a deformation which is hard to predict [10]. Also the tool holder and spindle support compliance must be taken into account. In general, their contributions to the compliance of the system cannot be neglected. Further, cell calibration is another important issue which directly effects the final quality achieved [11]. In robotic machining, the cell environment replaces the machine tool basement and the fixturing feature of the latter should be replaced with dedicated devices. In modern robotic cells, offline robot programming methods are used for complex robot tasks, such as milling or grinding. State of the art CAD/CAM software [12] for automatic path generation requires a close matching between the CAD representation of the work cell and its real environment. Current approaches are based on CAD knowledge of the cell, devices (e.g. tool holder) and robot, which provide extreme flexibility, but impose to adopt further calibration strategies to fulfil process 
accuracy requirements. Following the common approach of cell calibration position and orientation of cell components are computed using vision-based automated algorithms [13], [14].

\subsection{Robot Dependent Errors}

Within the mechanical robot structure two categories of errors can be distinguished: Geometrical errors and non-geometrical errors [8]. The former encompasses all the deviation due to imperfect geometries, mating or assembly errors, and these errors exist whether the robot is moving or not. The latter include all the sources related to the dynamical behaviour of the robot. In addition, unlike the former, they are time-varying and change in magnitude during manipulator operations. The main effect of both of these sources is causing discrepancies between the real robot and its kinetostatic and dynamic model from which its characteristics are derived [15] and on which control is based [16].

a) Geometrical errors: Geometrical errors, which are generally compensated by calibration, arise from manufacturing or machining tolerances of robot components. Tolerances introduce variations in link geometry, as well as some variation in the orientation of the joints after link assembly and non-linearities in the reducers. Then these errors will propagate to cause inaccuracy in the pose of the TCP. Links tolerances are not the unique source of geometrical errors. Joint errors in the axes are produced during the assembly of the various joint components due to clearance in motor and geared transmission mechanisms, backlash and bearing run-out errors. Backlash effects are a function of the geometrical looseness of the reducers produced when they are mated together. These errors can make a significant contribution, even larger than that due to geometric tolerances, to robot positioning accuracy [17], [18]. Yet as in robot machining initially a cell calibration and a referencing procedure of the real position of the workpiece are performed, only nonlinearities of the gears are considered in this paper. As the robot locally shows a rather good accuracy the impact of most geometrical errors (except nonlinearities of gears) can be reduced to errors in tool calibration (transformation from tool to TCP of the robot), nonlinearities and measurement errors of the applied sensors. Yet these errors may vary depending on the individual circumstances as disturbances such as dust, conservation liquid and burrs of the workpiece may introduce additional errors. 


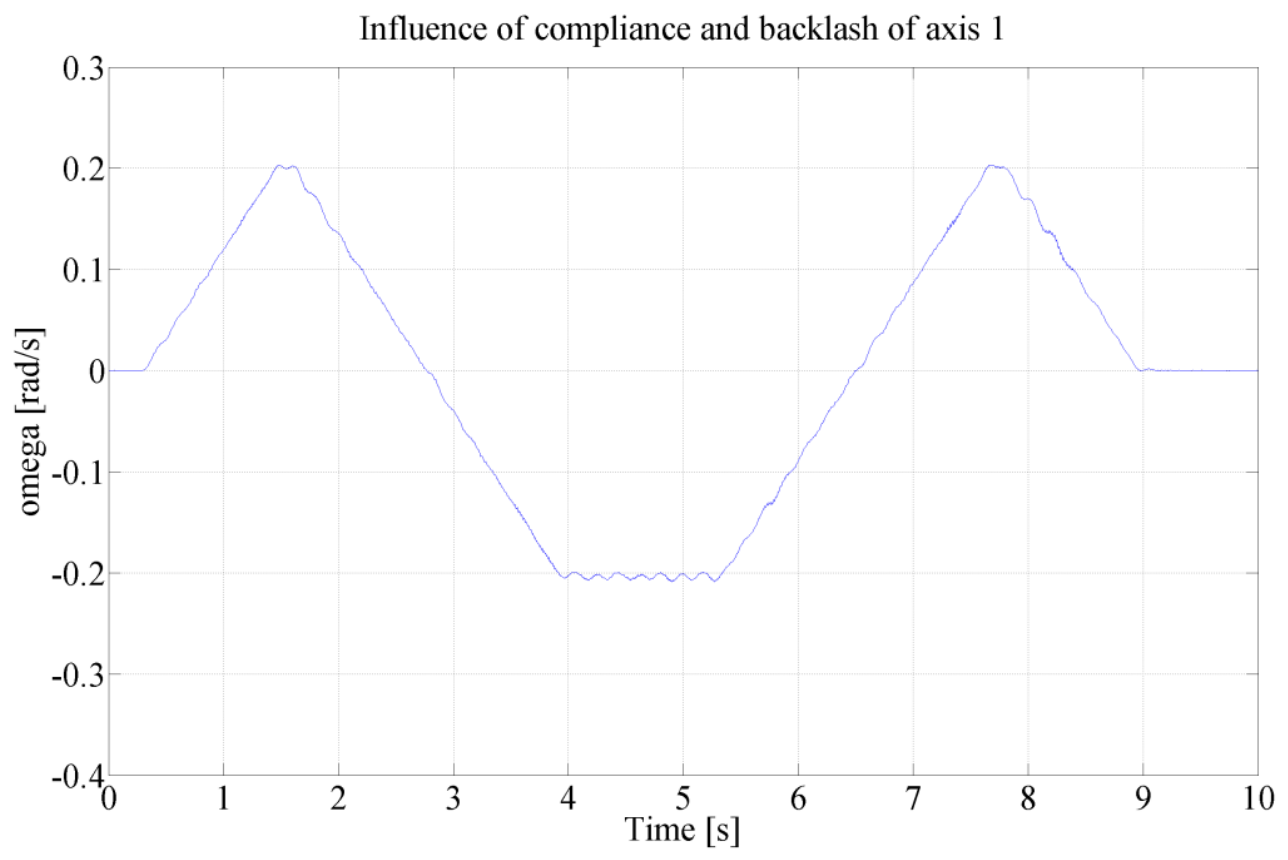

Fig. 2 Influence of compliance and backlash of axis 1.

b) Non-geometrical errors: Non-geometric errors also occur in a local environment and therefore cannot be compensated for by cell calibration. They arise from structural deformations of load-transmitting components, links and energy-transforming devices as well as from wear and nonlinear effects such as nonlinear stiffness, stick-slip motion and hysteresis in servo drives [19], [20]. The compliance errors are due to the compliance of the links and joints under inertial and external load. In particular, joint compliance results from the torsional stiffness of the gearbox and the output drive shaft actuating the joint. Besides, the masses of the links cause an additional torque on the gears due to gravity effects. Especially during machining, forces add on the load of the gears and cause additional deflection. Link and joint compliance, causing the deflection of the links and finally the TCP, contribute up to $8-10 \%$ of the position and orientation errors of the TCP [8].

In addition, joint, and to a less extent link, compliance causes vibrations of the robot structure during its movements. Especially, when the industrial robot is driven with high speed, the industrial robot has large vibrations caused by the speed reduction mechanism [21]. Moreover, when the load on the TCP changes rapidly, or robot is undergoing fast movement, the resonant phenomenon will appear. Compliance and backlash are the two most effective influences of a robot's gears and drives. The natural damping of such systems is very low and yields to a slow decay characteristic of torsional oscillations [20], [22], [23]. In addition, backlash yields high torque impulses 
which can excite torsional vibrations. In Fig. 2 these effects of first axis measured on the TCP of a KR125 are demonstrated. Further measurements on the stiffness of joint 1 allowed the identification of its compliance as well as the identification of the backlash value (see setup in Fig. 5). Forces and wrenches are captured with an ATI sensor theta SI-2500-400 on the TCP and transformed to the first joint. Lasertracker measurements capture deflections of joint 1 and are transformed to rotational deformations. Fig. 3 shows a backlash of $1.5910^{-4} \mathrm{rad}$, a compliance of $2.78^{*} 10^{-7} \mathrm{rad} / \mathrm{Nm}$ for negative torque and a compliance of $8.14 * 10^{-7} \mathrm{rad} / \mathrm{Nm}$ for positive torque. Assuming a lever of $1.5 \mathrm{~m}$ a realistic load on the TCP of $300 \mathrm{~N}$ caused by a machining process would result in a torque of $450 \mathrm{Nm}$ and a deflection of approximately $0.19-0.55 \mathrm{~mm}$. Machining experiments in aluminum also show the great impact of backlash (see Fig. 4).

In robotic machining processes, the force induced deflection of the robot structure is the single most dominant source of error. Even though all components of an industrial robot contain intrinsic compliance, the major compliance can be assigned to the gears. Other important sources of errors inside the mechanical structure are wear of the parts and the internal heat sources such as motors and bearings. Wear of the parts is strictly related to friction, in particular stiction, which in turn depends on temperature, joint applied torque and rotating speed [24].

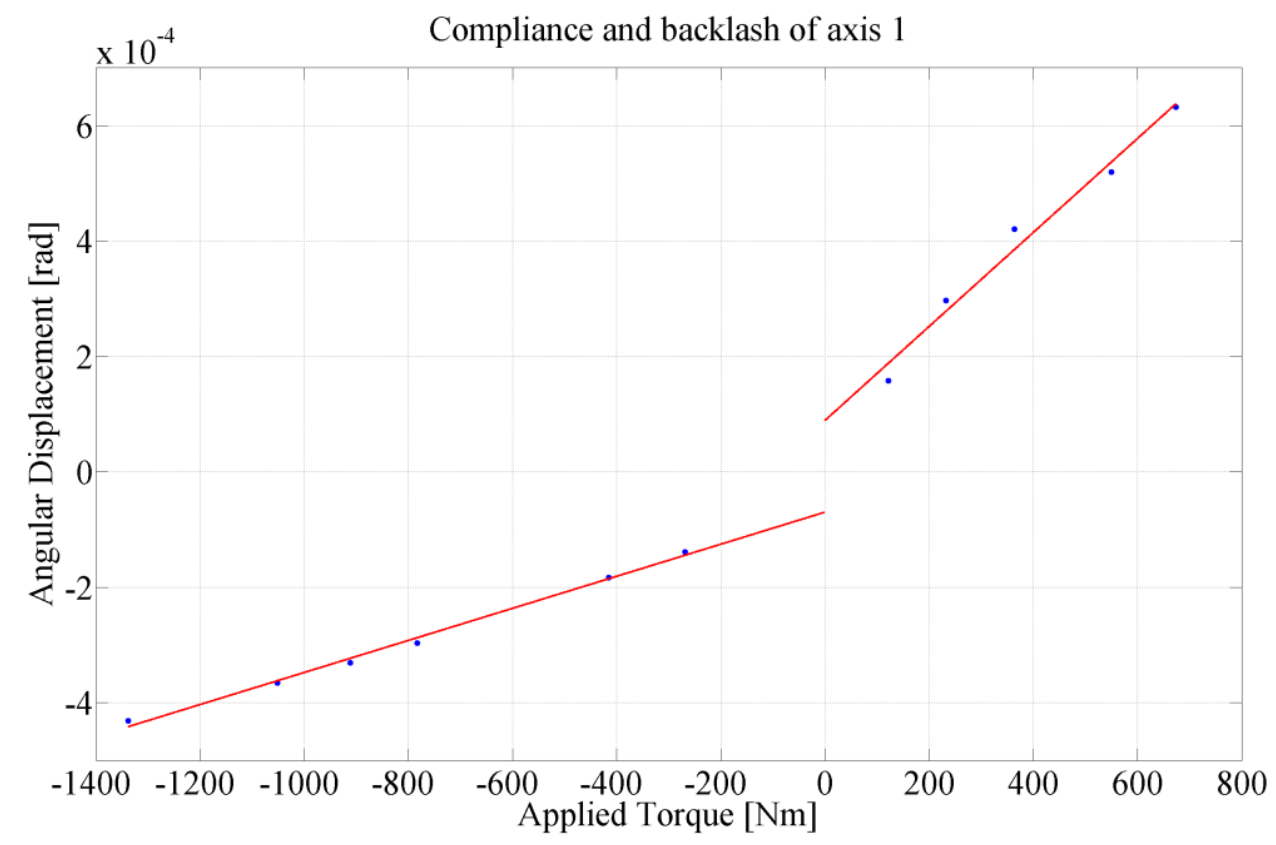

Fig. 3 Compliance measurements of KR125 axis 1. 


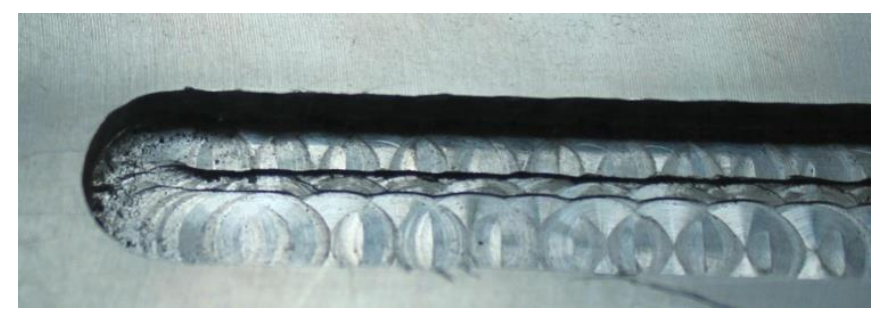

Fig. 4 Impact of gears backlash when machining in aluminum.

c) System Errors: Errors in this category include those caused by improper calibration, sensor measurement errors, control implementation errors and numerical round-off errors in the computer used for control. Sensor error is due to the joint angle sensor resolution and mounting. Due to the biggest lever axis 1 has the biggest impact on the TCP. When positioned in machining configuration minimal movements of $2 \mu \mathrm{m}$ could be identified on the TCP. Control and algorithmic errors are related to the geometrical model implemented in the controller. Especially for model-based controls precise and accurate models of the nonlinearities are required [25]. Furthermore, also the controller sampling time contributes to these errors especially in a real-time context [26].

\subsection{Process Dependent Errors}

In machining applications the most important source of position errors is the machining force. The machining force in an aluminium-milling process can be hundreds of Newton, consequently the force induced error reaches values up to $1 \mathrm{~mm}$ [27] (compare Fig. 6 and Fig. 7). The structure of the robot transmits this force to the workpiece according to its mechanical characteristics. The values of the machining forces depend on the process parameters: spindle speed, axial depth-of-cut, radial depthof-cut and chip load. They result in a specific value for the material removal rate value (MRR). In traditional machining application, feed is kept constant in spite of the variation of depth of cut and width of cut [28]. This will introduce a dramatic change of MRR, which would result in heavy changes in the machining force. The lubrication system is another important factor, especially for the final quality of the workpiece. The lubricating oil reduces the contact friction coefficient between the workpiece and the cutter, moreover this contributes to avoid the first type of chatter. The effects are measurable on the final quality surface of the machined part (e.g. roughness). Chatter is one of the major reasons preventing the adoption of robot for machining process [29]. At specific combinations of the foregoing parameters and due to thermo-mechanical 
effects on the chip formation (primary chatter) and regeneration of waviness of the surface of the workpiece caused by the vibration of the cutter (secondary chatter), the amplitude of cutting force increases and produces heavy vibrations on the robot and then on the TCP which interact with the workpiece [30]. As a result the surface of the workpiece becomes non-smooth.

\section{Analysis of Errors in Robot Machining}

Whereas the previous Section explained the sources of errors in robot machining in detail, this Section aims at describing the resulting effects. The mapping of sources and effects allows a final evaluation where the major errors in robot machining result from and which sources need to be addressed in order to improve quality when machining with industrial robots.

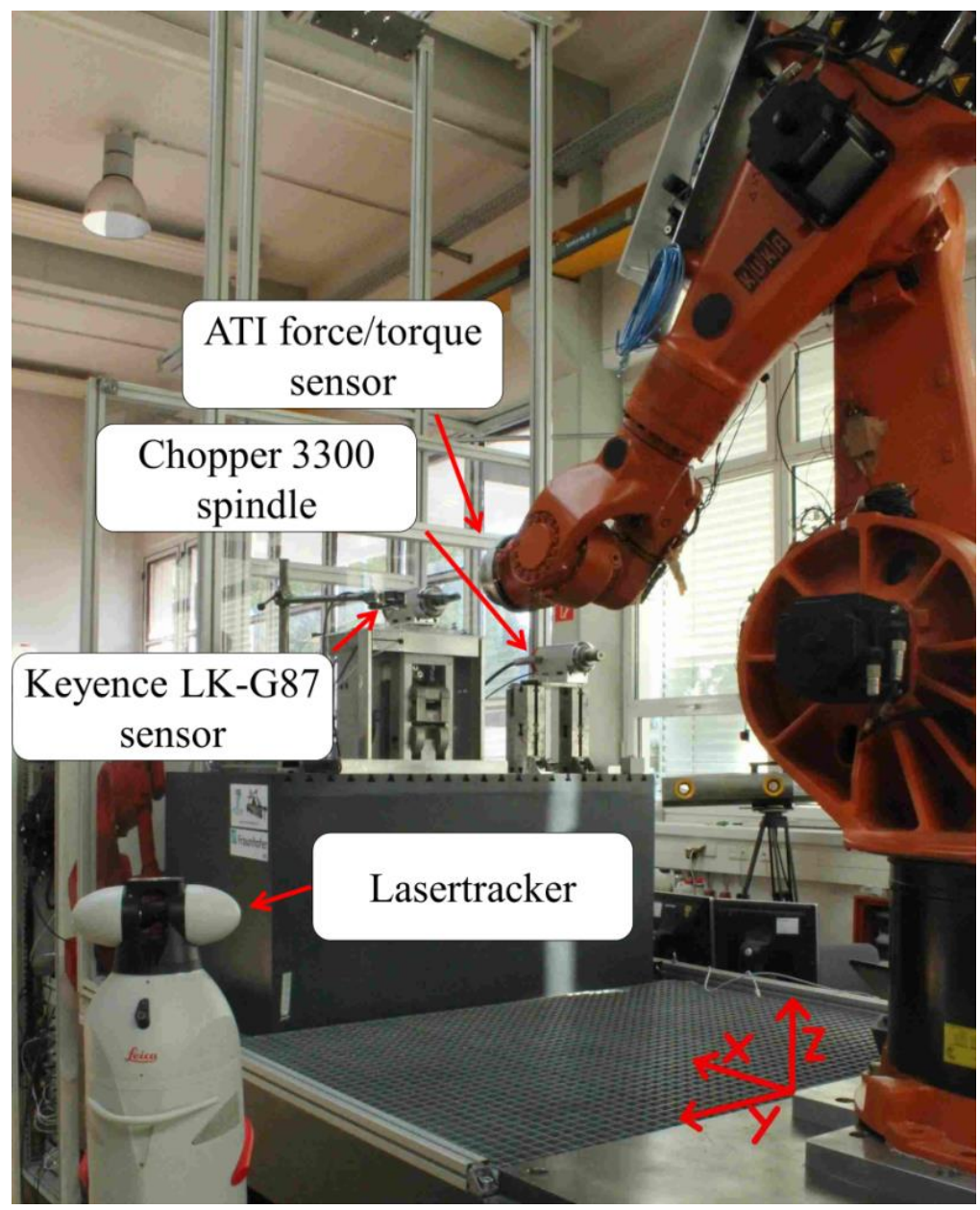

Fig. 5 Experimental setup with machine bed, KUKA KR125 robot, ATI force/torque sensor, Chopper 3300 spindle, Keyence LK-G87 1D-Lasersensor and 3D Leica Lasertracker. 


\subsection{Experimental Setup}

A KR125 from KUKA is used for the experiments (see Fig. 5). It is driven by a Beckhoff TwinCAT CNC and therefore optimized for the machining process. A Chopper 3300 spindle from Alfred Jaeger is used together with an $8 \mathrm{~mm}$ end mill tool with four teeth from Hoffmann Group. A Leica Absolute Tracker AT901 is used to measure the robot behaviour and to determine parameters of the error sources. The tracker can perform three dimensional measurements at $1 \mathrm{kHz}$, with an error of ErrLT $<20 \mu \mathrm{m}$ for the chosen area. A one-dimensional Keyence LK-G87 laser triangulation sensor is used in order to capture the influences of the surroundings on the robot. Robot and spindle are mounted on a 14 tons machine bed in order to decouple the cell from the surroundings. The lab is on the first floor over the basement.

\subsection{Robot in Machining Operation}

The robot in a machining operation is a complex system. The characteristic vibrations of the robot are combined with the oscillations due to the machining process. A machining example in ST-37 steel is chosen in order to demonstrate the typical effects in robot machining. The spindle speed is set to $10000 \mathrm{rpm}$ and the feed is defined as $1000 \mathrm{~mm} / \mathrm{min}$. Using a tool with four teeth, the process parameters allow to evaluate the fundamental tooth passing (or first harmonic) frequency which value is $\mathrm{f}=$ 666.7 Hz. Machining is performed in full width cut. As the robot shows different properties when moving in different directions two experiments were performed:

- Machining a straight line following the y-axis (robot base system)

- Machining a straight line following the z-axis (robot base system)

First of all, the deflection of the robot when entering the material should be pointed out. In full width cut process forces are most present in feed direction and orthogonal to feed [31]. Due to the limited stiffness and these process forces the robot is deflected from its targeted path (Fig. 6 and Fig. 7). As the robot in the used configuration is much more compliant in z-direction than in y-direction, the deflection orthogonal to path when machining in y direction is bigger. Secondly, the frequency analysis of the signal shows interesting results. As the attachment of the spindle is considered to have higher eigenfrequencies, due to greater stiffness and lower mass compared to the robot, all lower frequencies can be assigned to the robot. It is obvious that the dominant frequency can be found at $5.93 \mathrm{~Hz}$ and $23.77 \mathrm{~Hz}$. As the two machining scenarios cover the most compliant and the stiffest configuration of the robot it can be concluded that 
Position and FFT when machining in y-direction
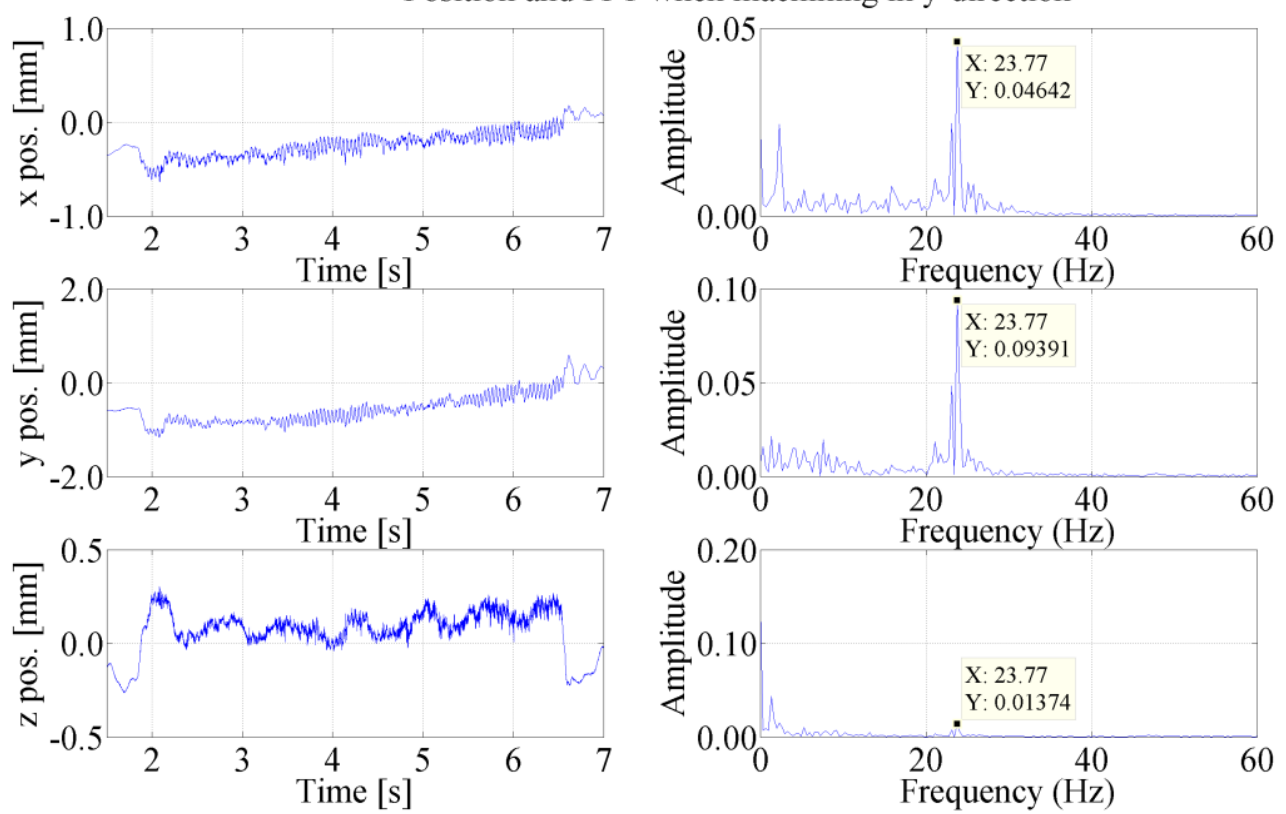

Fig. 6 Position and FFT when machining in y-direction.

Position and FFT when machining in z-direction
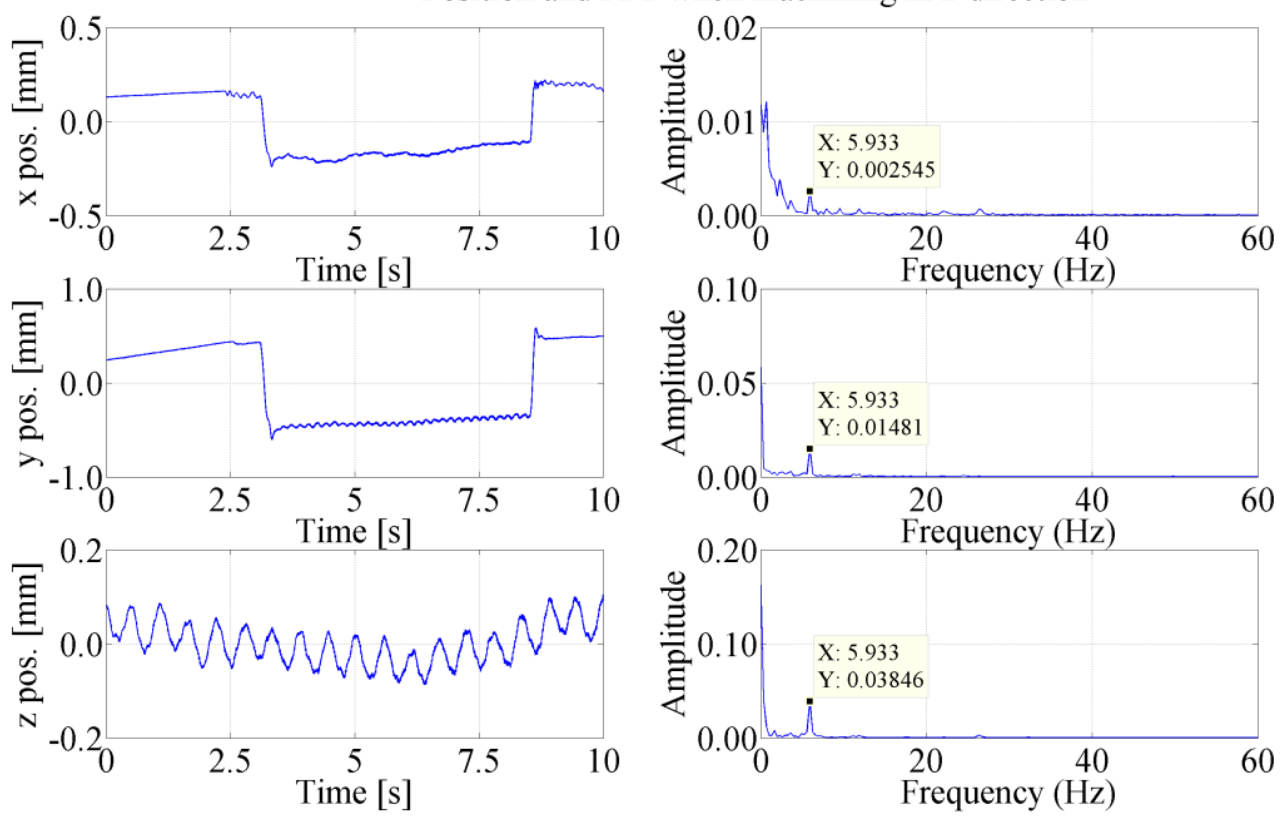

Fig. 7 Position and FFT when machining in z-direction.

the bandwidth of the robot varies between these two values depending on its configuration. Finally also the nonlinearities of the gears are clearly visible with an amplitude of $\pm 0.1 \mathrm{~mm}$. They do no change with the speed of the robot but they show up as a low frequency in the FFT in the experiment. However, they do not limit the bandwidth of the robot but influence only the accuracy of the robot. 


\subsection{Robot in Free Space Motion}

In contrast to a robot in machining a robot in free space movement is normally not excited by external disturbances. When moving the TCP in z-direction the impact of compliance and backlash of all axes result in the characteristic eigenfrequencies already experienced in machining (compare Section 3). Fig. 8 shows position and frequency properties of the free space motion. It should be noted that not only frequencies but also amplitudes of the oscillations in machining and in free space motion are comparable. As expected the nonlinearities of the gears appear like in the machining experiment.

\subsection{Summary of Effects in Robotic Machining}

According to the previous Sections it can be concluded that the dominant frequencies in robot machining only depend on the mechanical properties of the robot. The effects can be traced back to the compliance and the backlash of the gears determining the frequency of position disturbances in the TCP. The results of all measurements describing the effects on the TCP are summarized in Table I. As expected, changing the configuration of the robot leads to different properties in terms of compliance and natural frequencies. This can be easily recognized in the final surface finishing (compare Fig. 4).

Position and FFT when moving in z-direction
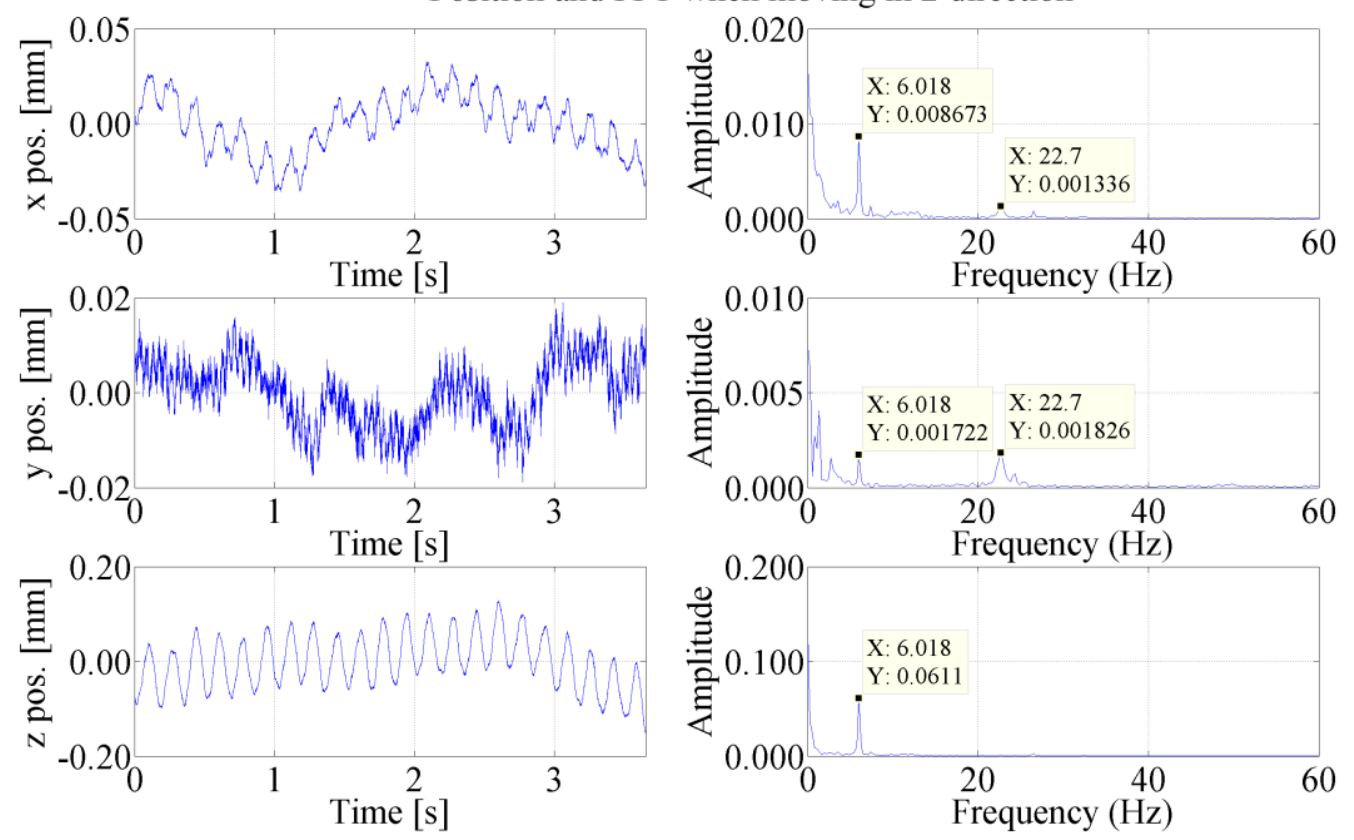

Fig. 8 Position and FFT when moving in z-direction. 
As in machining the exciting frequencies are always higher than the eigenfrequencies of the robot (compare Section 3.2), the robot is very likely to oscillate with its eigenfrequencies.

Table 1. Summary of effects in robot machining: Displacements and frequencies

\begin{tabular}{lrr}
\hline \multicolumn{1}{c}{ Experiment } & Displacement & $\begin{array}{c}\text { Dominant } \\
\text { frequency }\end{array}$ \\
\hline Static displacement when machining in y & $0.200 \mathrm{~mm}$ & - \\
Static displacement when machining in z & $1.000 \mathrm{~mm}$ & - \\
Static displacement when moving freely in z & - & - \\
Dynamics when machining y & $\pm 0.250 \mathrm{~mm}$ & $23.77 \mathrm{~Hz}$ \\
Dynamics when machining z & $\pm 0.050 \mathrm{~mm}$ & $5.93 \mathrm{~Hz}$ \\
Dynamics when moving freely in z & $\pm 0.070 \mathrm{~mm}$ & $6.02 \mathrm{~Hz}$ \\
Nonlinearities of gears when moving freely in z & $\pm 0.100 \mathrm{~mm}$ & - \\
Walking person passing & $\pm 0.020 \mathrm{~mm}$ & - \\
Pallet truck passing & $\pm 0.007 \mathrm{~mm}$ & - \\
\hline
\end{tabular}

\section{The COMET Approach to Robotic Machining}

The outlined investigations show that because of existing errors the wide and extensive use of industrial robotics is finally limited to less demanding tasks with (very) low accuracy and low material removal rate. As described in [32] those tasks are mainly deburring, deflashing and finishing purposes. Industrial robots intrinsic reconfigurability and adaptiveness are in fact crucial to cope with the latest requirements of extreme responsiveness and flexibility in production [33], [34]. In order to leverage smart manufacturing new approaches are necessary.

The COMET project addressed the robot machining challenge and developed a modular and configurable platform able to enhance the machining accuracy of standard industrial robots enabling cost-effective, first time right, robot machining [12]. As outlined in Section 2 the understanding of error sources was mandatory and used as foundation to formulate the design requirements.

An effective industry oriented robot machining requires proper error compensation solutions able to overcome the intrinsic performance limitations of standard industrial robots respect to machine tools. The COMET approach is focused on a novel modular and configurable machining error compensation platform that can be customized for specific application fields with different accuracy and performance. 


\subsection{Basic Concept}

In the COMET project two different adaptive error compensation approaches were developed: offline compensation based on the predictive calculation of the robot positioning errors and their consequent corrections, and online compensation based on the real-time measurement of the real robot TCP position for active compensation. The two approaches are based on four main modules, which address the influences discussed in Section 2:

1. A unique Kinematic and DynaMic representation of each Industrial Robot entity (KDMIR), including a methodology to determine the respective required model parameters. The respective modelling and parameter identification procedures are separately described in [35] and [36].

2. An integrated Programming and Simulation environment for adaptive generation of the machining path for Industrial Robots (PSIR), which builds upon unique robot models. The implemented mechanisms for inclusion of different (robot) models into the CAM environment are discussed in [37].

3. An Adaptive Tracking system for Industrial Robots (ATIR), which detects deviations from the desired robot path and initiates real-time corrective actions towards the robot controller.

4. A High Dynamic Compensation Mechanism (HDCM) which can perform additional positional corrections that exceed the robots mechanical bandwidth or its positional accuracy. The mechanism follows the idea of a 3D-piezo compensation mechanism previously presented in [38].

By combining these modules (summarized in Fig. 9), different configurations for the setup of the industrial robot machining cells are possible. The first important distinction has to be made between predictive error compensation applied offline during programming (KDMIR and PSIR) and the real-time compensation applied online during machining (ATIR and HDCM). Again for each subdivisions can be made, depending if certain sub-modules are integrated or not (e.g. online compensation only with feedback controlled robot or with superimposed control of robot and HDCM). These will be explained further in the Sections 4.2 and 4.3. With such modular platform it is possible to configure the robot cell optimizing the performance for a specific application. The cell layout can be designed with configurations where the robot moves the milling 
Controlled Variable: Position Spindle vs. Work Piece

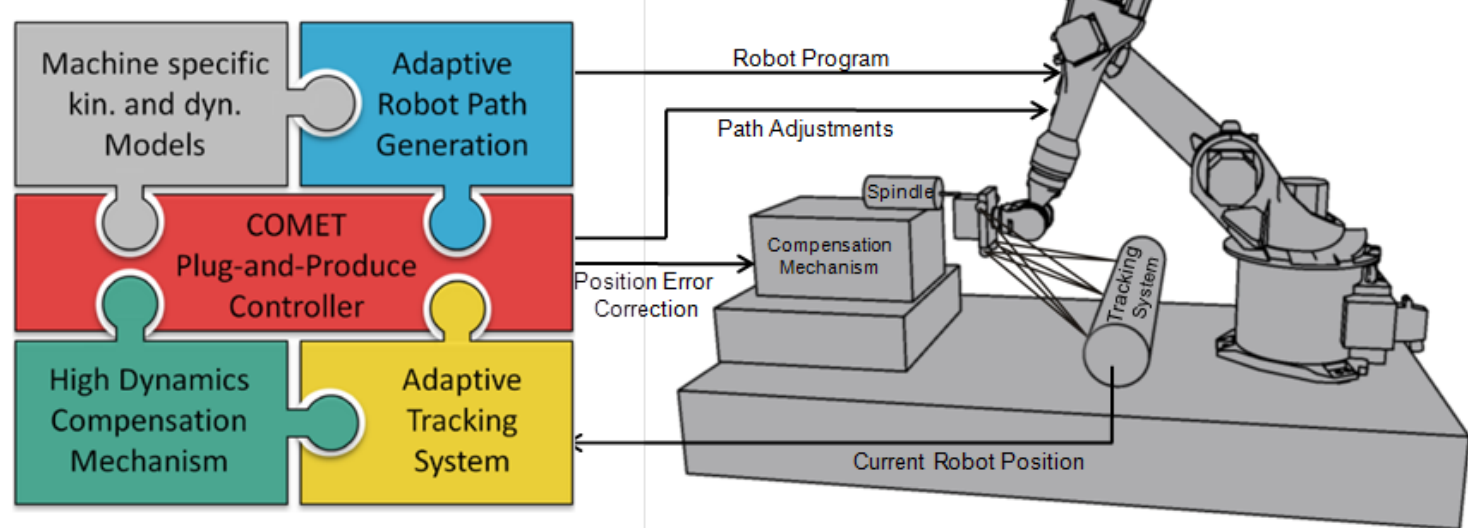

Fig. 9 Schematic summary of the COMET modules and overall approach [12]

spindle or the workpiece. Furthermore, the overall approach by principle is of general use and robot vendor independent.

\subsection{Offline Compensation}

The PSIR aims at realizing a complete, first time right, robot machining path program, avoiding the need of long and complex commissioning on the real robot cell.

The outcome of PSIR should be a complete and correct robot path, which does not require changes to be applied within the robot cell. This is an important requirement due to the usage for machining applications, where only an initial tool and workpiece calibration is possible (as also on regular CNC machines). Manual corrections of further points are not possible due to the huge number of tool path points. Workpiece based learning is often not acceptable due the long machining times and the high costs per workpiece. Therefore, the software needs to consider possible issues beforehand and either correct them directly or display them to the user for manual correction. In order to improve the achievable accuracy, robot dependent error sources (compare Section 2.2) have to be considered. The approach described in the following therefore aims at modelling and compensating not only geometrical and non-geometrical but also process dependent errors during robot program generation. The robot path is adapted according to the predicted deviations. Effectively the robot is not commanded to the desired pose, but to a pose that will end near the desired one, after all errors affected the robot arm. To foresee the positional errors of the robot, the robot is modelled with components reflecting the mechanical issues as described above, namely the optimized kinematic description and a coupled model of the robot joints, including backlash, friction and 
torsional stiffness for each joint. In order to utilize this robot model for compensation of the machining path, some additional information about the process is required to determine the forces acting on the tool during machining. Therefore, additional to the updated kinematic description and the joint-based robot model, a model to estimate the process forces is required, which again needs details from the CAM system about the material and tool as well as the engagement situation of the tool in order to give a valid output. Starting point of the offline compensation is a tool path defined within the CAM system. In contradiction to conventional machine tools this tool path - besides information about tool position and orientation - also includes information about the respective robot poses due to the additional degree-of-freedom. The subsequent chain of applied calculations after such a tool path has been generated is the following:

- Within the CAM system an engagement angle calculation is executed in order to predict the engagement situation of the tool within the material for each point of the tool path.

- Based on the predicted engagement situation of the tool, a 3D process force vector is calculated, predicting the magnitude and direction of the force working on the tool tip (for more information on the force calculation based on Kienzle [39] the reader is referred to [35]). The force calculation considers both the machined material as well as the tool geometry. The calculated force is the force affecting the robot, either directly (if the robot is moving the spindle) or indirectly as reaction force (if the robot is moving the work piece).

- With the combined information on how the robot should move according to the CAM and which forces affect the tool (and thus the robot) an external simulation using the robot model on joint basis can be run. It determines first how the robot would actually move due to the joint based effects in particular geometric and non-geometric errors like backlash and friction in the gears or compliance of the joints) and consecutively generates altered program points to compensate for these effects.

- In a last step, a kinematic calibration is applied, which again alters the points of the tool path, using both the nominal kinematic values (which also the robot controller uses internally) and optimized parameters based on measurements (which reflect the real kinematic structure). 
At the end, a regular robot program is generated using a post-processor for the used robot brand. As all compensations are done by adapting the Cartesian points in the robot program and no additional information has to be transferred towards the robot, application of this approach is independent of the robot brand. Disadvantage of the compensation per program point is the hereby limited resolution [37]. Resolution enhancement is only possible up to certain limits, determined e.g. by controller memory or cycle time. Although internally the separate simulations can be run with higher resolutions, but for the post-processed program these limits persist. The described program generation chain cannot only be used to generate compensated robot paths, but alternatively can also be used to simulate the behaviour of the robot without compensation. In combination with a material removal simulation the machining outcome when using the uncompensated robot can be visualised in order to determine potential geometrical errors and the overall achievable machining accuracy.

In order to apply the offline compensation on a certain robot, different model parameters have to be determined first, which are then stored in a so-called Robot Signature file (this file is created for each unique robot and can be accessed by the CAM system to load the respective model parameters). Different measurement and parameter identification methods have been developed or utilized. The optimized kinematic parameters are identified using an optical tracking system and measurements of the end effector in free space movements. For the determination of the joint based parameters an identification method for kinematic parameters [40] (based on the idea of generating a closed kinematic chain by rigidly clamping the robot to the environment) was applied to the identification of joint properties [36], [41]. For the identification of the material and tool dependent parameters a method which processes force data captured during machining of a test workpiece was developed [35].

\subsection{Online Compensation}

This Section describes an approach for the online error compensation in the range of micrometers during machining tasks of industrial robots. The concept takes into account data acquisition, sophisticated data fusion and external compensation using a parallel 3D-piezo-actuator compensation mechanism (HDCM). In this case the robot positions the workpiece relative to the tool. The tool is mounted on the HDCM which allows the adjustment of the tool in the working range of the HDCM. 

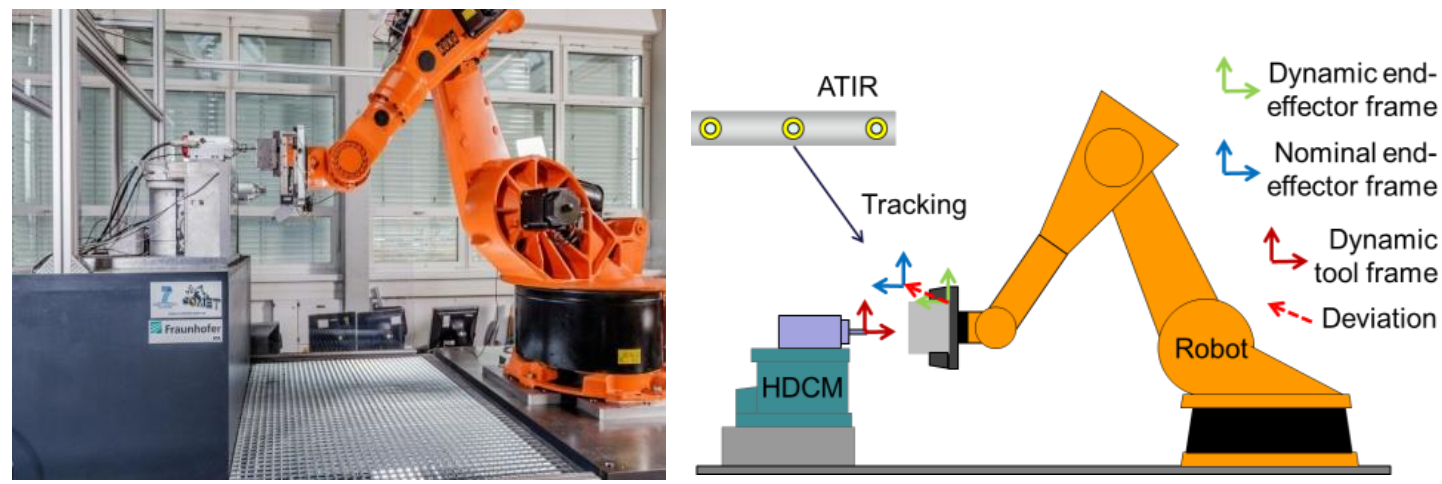

Fig. 10 (a) Experimental set-up for online compensation at Fraunhofer IPA, (b) Measured frames of the set-up

Considering the compensation idea there are two mechanical systems for compensation. Firstly, the robot which is comparably slow but has a large work space. The second system, the HDCM, provides conversely to the robot fast movements in a limited geometric work space of approximately $0.5 \mathrm{~mm}$. As a result the deviation between nominal end-effector frame and dynamic end-effector frame relative to the dynamic tool frame needs to be adjusted. This determines the control error, which summarizes robot dependent as well as process dependent errors. To fully understand the set-up the deviation is depicted in Fig. 10. The online measurements are obtained by using a metrological tracking system. Therefore, path deflections of the robot e.g. generated by the backlash or compliance can be measured [42]. For instance, the Nikon Metrology K600 system allows simultaneous tracking of two frames. First results of the usage of the tracking system for robot control in machining applications have been published in [43]. In addition to the dynamic measurements the previously outlined cell calibration is initially performed. As a result the nominal set-up for programming is matched with the actual set-up based on the usage of metrological tracking system. One could obtain values of static frames from CAD. But in practice, despite accurate construction geometrical and system errors could still exist. Therefore, a manual probe is used to measure all static frames as references. Flashing LEDs as parts of the K600 system are attached to HDCM and robot to obtain the moving frames. This allows the detection of the dynamic end-effector frame and the dynamic tool frame. Taking into account that the HDCM is designed for fast but small compensations, the saturation of each axis of the HDCM has to be avoided. Therefore the determined error is partitioned between robot and HDCM. As robot and HDCM behaves differently smart splitting between both systems is introduced. This is realized in [44] using a mid-ranging control 
approach of a fast manipulator with limited work space (HDCM, referred to as micro manipulator) and a slow manipulator with big work space (robot, referred to as macro manipulator).

In order to fulfil the criteria of high dynamic compensation a progressive design is implemented based on the experiences described in [45], [46]. As shown in [38] piezoactuators combined with elastic solid state joint-lever-mechanisms are appropriate for smooth movements. Opposed to conventional bearings friction, play and backlash are significantly reduced. The chosen approach uses instead of a serial mechanism a parallel actuation to improve the dynamical behaviour [46]. The reduction of the moved mass allows to improve the dynamics. Furthermore, the real achievable working range depends strongly on the stiffness of the transmission system. In particular, the piezo actuators only allow actuation up to a certain force, because of its bounded stiffness. The additional load, therefore, influences the working range. Piezo-actuators are equipped with strain gauge sensors. Additional capacitive sensors are placed underneath the movable plate. Those capacitive sensors are aligned with the axes directions. Thus, each capacitive sensor allows the tracking of the movable plate in one compensation direction. A feedback control approach realizes the automatized positioning of each axis, respectively. Input voltage is set deforming the piezo-actuator. The proposed control scheme for each compensation axis takes into account:

- Inner PID controller for feedback from strain gauge sensors in piezoactuators for handling parameter uncertainties and disturbances.

- Outer model based controller for position control of the end-effector plate where the machining spindle is attached. The control of a piezo-actuated high-dynamic compensation mechanism is presented in [47], [48]. The control variable is measured by the capacitive sensors.

\section{Cell Setups and Demonstration Strategy}

Experimental validation was made in a total of eight demonstration setups, covering different basic setups (spindle on robot or on fixture), different robot brands (ABB, KUKA, YASKAWA Motoman) and different application cases. Depending on the requirements of the respective demo application, a specific set of the modules as described in Section 4.1 was applied using the PSIR as basic component for all cells. Applications range from manufacturing of aero and automotive components (complete 


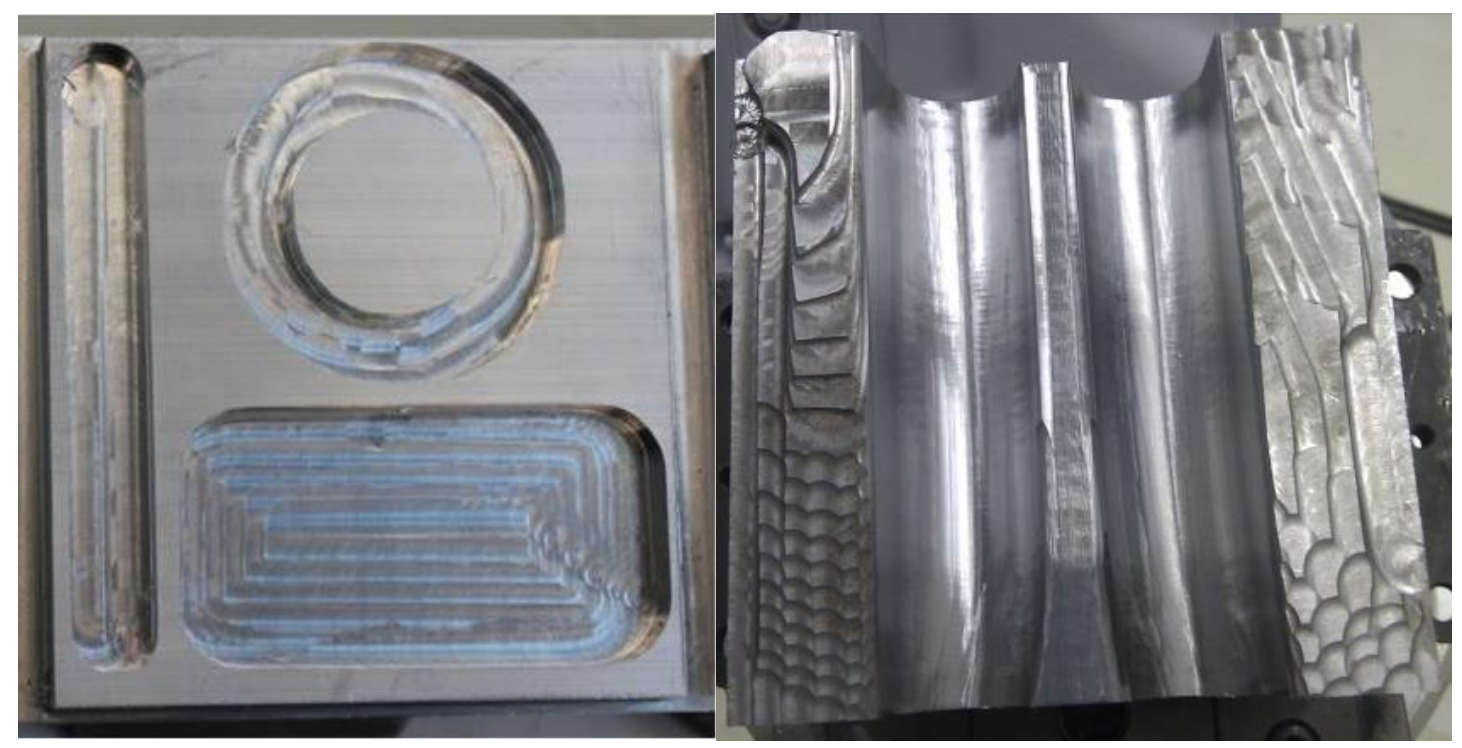

Fig. 11 (a) Test features used for validation of the different compensations, (b) Machining of an industrial demonstration part (mould-and-die)

machining and finishing processes for aluminium and Inconel parts) to mould making (complete machining in hardened steel, requiring high accuracies). First tests were made with simplified geometries on test workpieces (see Fig. 11a) to show the general feasibility to machine the requested materials and to validate the developed compensation modules (see Table 2). Further details on the experimental conditions and components are described in [37], [44]. Depending on the complexity of the compensation, this validation was carried out in several subsequent steps, e.g. different calculation steps for offline compensation (as described in Sec. 4.2) were first tested separately before validating the complete compensation chain. Secondly the developed methods and components were used to machine industrial parts from the various industrial sectors, highlighting the combination possibilities of the modular approach. Fig. 11b shows such a demonstration part (with rough machining on the sides and semifinishing in the middle) made from hardened steel (X37CrMoV5-1). For the shown demo part (depending on applied compensation) a geometrical accuracy of $<0.4 \mathrm{~mm}$ can be achieved.

Although the COMET approach is designed robot brand independently, certain restrictions for some robot cells limit the applicability of the developed compensation methods. This is either due to missing access to (controller) parameters required during the identification of the model parameters or as consequence of missing possibilities to feedback correctional values for the online compensation in sufficient cycle time.

The machining of the industrial parts shows that machining with industrial robots can be an alternative to the use of dedicated machine tools, although the actual benefits are 
clearly depending on the specific use-case and material. For soft materials machining results comparable to machine tools are possible, but also for more challenging materials like hardened steel, robots can be a viable alternative. The applied compensation approaches allow manufacturing within tolerances which are sufficient for roughing and semi-finishing for hard materials, so that capacities can be taken off the costly machine tools for these steps where their high accuracy is not required. The biggest remaining geometrical deviations occur where process conditions change rapidly (e.g. for material entry or exit). For less demanding materials complete machining of the industrial parts is possible.

Table 2. Summary of benefits with respect to proposed approaches [37], [43], [44]

\begin{tabular}{llll}
\hline Approach & Material & Machined geometry & $\begin{array}{l}\text { Experimentally } \\
\text { determined } \\
\text { deviations [mm] }\end{array}$ \\
& & & 0.500 \\
Uncompensated & Aluminium & Pocket: length $70 \mathrm{~mm}$, & -0.240 \\
& & width $37.5 \mathrm{~mm}$ & 0.20 \\
Offline compensation (K) & Aluminium & Pocket: length $70 \mathrm{~mm}$, & 0.46 \\
& & width $37.5 \mathrm{~mm}$ & 0.07 \\
Offline compensation (JB) & Aluminium & Pocket: length $70 \mathrm{~mm}$, & 0.05 \\
& & width $37.5 \mathrm{~mm}$ & \pm 0.60 \\
Uncompensated & & & \pm 0.20 \\
Online compensation (ATIR) & Steel & Circle (diameter $70 \mathrm{~mm}$ ) & \pm 0.10 \\
Online compensation (ATIR+HDCM) & Steel & Circle (diameter $70 \mathrm{~mm})$ & Circle (diameter $70 \mathrm{~mm}$ ) \\
\hline
\end{tabular}

Another conclusion that can be drawn is that - besides the improvements possible with compensations - a fair amount of quality can be gained already by selection of appropriate machining strategies. Not only that a proper strategy can already enhance the workpiece quality, the resulting - more stable and predictable - cutting process offers a much more reliable basis for application of the compensations.

\section{Discussion and Conclusions}

The presented paper analyses the relevant sources of errors when machining with industrial robots. The full mechanical chain from the environment to the flange and the robot controller are considered. The most important sources are identified and characterized. Experiments in machining and experiments in free space motion show 
that compliance and backlash are the most dominant sources. However, when trying to achieve an accuracy of $<100 \mu \mathrm{m}$ also the disturbances from the environment and errors from cell calibration need to be taken into account. Position and frequency analysis demonstrate the dependency on the robot configuration and identify the stiffest configuration of the robot. Based on the analysis a compensation of compliance and backlash can be identified as being most effective. Calibration of the robot kinematics and the calibration of the work cell can improve positioning accuracy and results also in better precision in machining. Proper decoupling of the cell components from the environment and from each other can reduce process disturbances further. The intrinsic oscillation of a serial robotic system can only be eliminated by external devices.

From the machining experiments so far it can be concluded that, besides the improvements that can be achieved using the different proposed compensation methods, also the general cell setup and the selected machining strategy have an important influence both on the achievable geometrical accuracy and the resulting surface quality. Ensuring stable cutting conditions is the foundation for reliable application of the compensation approaches. While the general proposed approach is robot brand independent, the implementation at the demo cells showed differences in applicability depending on the respective brand but also differences between different types of the same brand. The heterogenic situation on the robot market therefore still is an obstacle for each solution aiming at improving robot machining accuracy.

Further work is required on the combination of the compensations applied offline and online. Up to this point only one group of compensations can be used at once. Obstacles here are the need to transfer both the compensated and the nominal path throughout the whole process chain, as well as the synchronization between the different representations of machining processes in general (ideal and actual movements and forces) and the tool path in particular (point-based in the robot program, but required time-based for the online compensation).

Finally, future works may address the deeper integration with robot vendor's controllers for real-time feedback loops through external sensors, actually felt as the main performance limit. Furthermore, the analysis of the on-going tests final results will stimulate future development guidelines on the COMET approach basis. 


\section{ACKNOWLEDGMENTS}

The research work reported here was supported by the European Commission under the Seventh Framework Programme (FP7/2007-2013) within the project COMET under grant agreement \#258769.

\section{References}

[1] Tolio T, Urgo M (2013) Design of flexible transfer lines: A case-based reconfiguration cost assessment. In: Journal of Manufacturing Systems 32 (2): 325-334.

[2] International Federation of Robotics (2013) World Robotics 2012, Statistical Yearbook.

[3] Liang J, Bi S (2010) Design and experimental study of an end effector for robotic drilling. In: International Journal of Advanced Manufacturing Technology 50 (1-4): 399-407.

[4] Schneider U, Ansaloni M, Drust M, Leali F, Verl A (2013) Experimental investigation of error sources in robot machining. In: International Conference on Flexible Automation and Intelligent Manufacturing (FAIM), pp. 14-26, Porto, Portugal.

[5] Standard ISO 9283 (1998) Manipulating industrial robots - Performance criteria and related test methods.

[6] Siciliano B, Khatib O (2008) Handbook of Robotics. New York: Springer.

[7] Shiakolas PS, Conrad KL, Yih TC (2002) On the accuracy, repeatability, and degree of influence of kinematics parameters for industrial robots. In: International Journal of Modeling and Simulation 22: 245-254.

[8] Mustafa SK, Pey YT, Yang G, Chen I (2010) A Geometrical Approach for Online Error Compensation of Industrial Manipulator. In: IEEE/ASME International Conference on Advanced Intelligent Mechatronics, pp. 738-743, July 6-9, Montreal, Canada.

[9] Breth JF, Vasselin E, Lefebvre D, Dakyo B (2005) Determination of the Repeatability of a Kuka Robot Using the Stochastic Ellipsoid Approach. In: IEEE International Conference on Robotics and Automation, pp. 4339-4344, Barcelona, Spain.

[10] Heisel U, Richter F, Wurst K-H (1997) Thermal behavior of industrial robots and possibilities for errors compensation. In: CIRP Annals - Manufacturing Technology 46: 283-286.

[11]Zhan Q, Wang X (2012) Hand-eye calibration and positioning for a robot drilling system. In: International Journal of Advanced Manufacturing Technology 61(5-8): 691-701.

[12]Lehmann C, Pellicciari M, Drust M, Gunnink JW (2013) Machining with industrial robots: the COMET project approach. In: International Conference on Flexible Automation and Intelligent Manufacturing (FAIM), pp. 27-36, Porto, Portugal.

[13]Pan Z, Polden J, Larkin N, Van Duin S, Norrish J (2012) Recent progress on programming methods for industrial robots. In: Robotics and Computer-Integrated Manufacturing 28: 87-94.

[14] Tarn TJ, Song M, Xi M, Ghosh BJ (1996) Multi-Sensor Fusion Scheme for Calibration-Free Stereo Vision in a Manufacturing Workcell. In: IEEE International Conference on Multisensor Fusion and Integration for Intelligent Systems, pp. 416-423, Washington DC, USA. 
[15]Legnani G, Tosi D, Fassi I, Giberti I, Cinquemani S (2010) The "point of isotropy" and other properties of serial and parallel manipulators. In: Mechanism and Machine Theory 45: 1407-1423.

[16]Dietz T, Schneider U, Barho M, Oberer-Treitz S, Drust M, Hollmann R, Hägele M (2012) Programming System for Efficient Use of Robots for Deburring in SME Environments. In: $7^{\text {th }}$ German Conference on Robotics (Robotik), Munich, Germany.

[17] Oh YT (2011) Influence of the joint angular characteristics on the accuracy of industrial robots. In: Industrial Robot38:406-418.

[18]Erkaya S (2012) Investigation of joint clearance effects on welding robot manipulators. In: Robotics and Computer-Integrated Manufacturing 28:449-457.

[19] Gong C, Yuan J, Ni J (2000) Nongeometric error identification and compensation for robotic system by inverse calibration. In: International Journal of Machine Tools and Manufacture 40: 2119-2137.

[20]Ruderman M, Hoffmann F, Bertram T (2009) Modeling and Identification of Elastic Robot Joints with Hysteresis and Backlash. In: IEEE Transactions on Industrial Electronics 56: 3840-3847.

[21] Kumagai S, Ohishi K, Miyazaki T (2009) High Performance Robot Motion Control Based on Zero Phase Error Notch Filter and D-PD Control. In: IEEE International Conference on Mechatronics, pp. 1-6, Malaga, Spain.

[22] Marton L, Lantos B (2009) Friction and backlash measurement and identification method for robotic arms. In: IEEE International Conference on Advanced Robotics, pp. 1-6, Munich, Germany.

[23] Thomsen S, Fuchs,FW (2009) Speed Control of Torsional Drive Systems with Backlash. In: $13^{\text {th }}$ European Conference on Power Electronics and Applications, pp. 1-10, Barcelona, Spain.

[24] Carvalho Bittencourt A, Wernholt E, Sander-Tavallaey S, Brogardh T (2010) An Extended Friction Model to capture Load and Temperature effects in Robot Joints. In: IEEE International Conference on Intelligent Robots and Systems, pp. 6161-6167, Taipei, Taiwan.

[25] Jin M, Jin Y, Chang PH, Choi C (2009) High-Accuracy Trajectory Tracking of Industrial Robot Manipulators Using Time Delay Estimation and Terminal Sliding Mode. In: $35^{\text {th }}$ Annual Conference of IEEE Industrial Electronics, pp. 3095-3099, Porto, Portugal.

[26] Merlet JP (2009) Interval analysis for certified numerical solution of problems in robotics. In: International Journal of Applied Mathematics and Computer Science 19: 399-412.

[27]Zhang H, Wang J, Zhang G, Gan Z, Pan Z, Cui H, Zhu Z (2005) Machining with Flexible Manipulator: Toward Improving Robotic Machining Performance. In: IEEE International Conference on Advanced Intelligent Mechatronics, pp. 1127-1132, Monterey, California, USA.

[28]Zhang H, Pan Z (2008) Robotic Machining: Material Removal Rate Control with a Flexible Manipulator. In: IEEE Conference on Robotics, Automation and Mechatronics, pp. 30-35, Chengdu, China.

[29] Pan Z, Zhang H, Zhu Z, Wang J (2006) Chatter analysis of robotic machining process. In: Journal of materials processing technology 173: 301-309.

[30] Quintana G, Ciurana J (2011) Chatter in machining processes: A review. In: International Journal of Machine Tools and Manufacture 51: 363-376. 
[31]Liu X-W, Cheng K, Webb D, Longstaf AP, Widiyarto MH (2004) Improved dynamic cutting force model in peripheral milling. Part II: experimental verification and prediction. In: International Journal of Advanced Manufacturing Technology 24: 794-805

[32] Surdilovic C, Dragoljub Zhao H, Schreck G, Krueger J (2012) Advanced methods for small batch robotic machining of hard materials. In: 7th German Conference on Robotics (Robotik), pp.1-6, 2122 May, Munich, Germany.

[33] Tolio T, Ceglarek D, ElMaraghy HA, Fischer A, Hu SJ, Laperrière L, Newman ST, Váncza J (2010) SPECIES - Coevolution of products, processes and production systems. In: CIRP Annals Manufacturing Technology 59 (2): 672-693, 10.1016/j.cirp.2010.05.008.

[34] Pellicciari M, Leali F, Andrisano AO, Pini F (2012) Enhancing Changeability of Automotive Hybrid Reconfigurable Systems in Digital Environments. In: International Journal on Interactive Design and Manufacturing 6: 251-263.

[35] Lehmann C, Halbauer M, Euhus D, Overbeck D (2012) Milling with industrial robots: Strategies to reduce and compensate process force induced accuracy influences. In: $17^{\text {th }}$ IEEE International Conference on Emerging Technologies \& Factory Automation (ETFA), pp. 1-4, Kraków, Poland.

[36]Lehmann C, Olofsson B, Nilsson K, Halbauer M, Haage M, Robertsson A, Sörnmo O, Berger U (2013) Robot Joint Modeling and Parameter Identification Using the Clamping Method. In: IFAC Conference on Manufacturing Modeling, Management and Control (MIM), pp. 813-818, Saint Petersburg, Russia.

[37]Lehmann C, Halbauer M, van der Zwaag J, Schneider U, Berger U (2013) Offline Path Compensation to Improve Accuracy of Industrial Robots for Machining Applications. In: Proceedings of $14^{\text {th }}$ Automation Congress, VDI-report 2209, pp. 147-152, Baden-Baden, Germany.

[38] Puzik A (2011) Genauigkeitssteigerung bei der spanenden Bearbeitung mit Industrierobotern durch Fehlerkompensation mit 3D Ausgleichsaktorik, Dissertation, University Stuttgart, Fraunhofer IPA.

[39] Kienzle O (1952) Bestimmung von Kräften an Werkzeugmaschinen. In: VDI-Z 94: 29-05.

[40] Bennett D, Hollerbach J, Henri P (1992) Kinematic calibration by direct estimation of the Jacobian matrix. In: IEEE International Conference on Robotics and Automation (ICRA), pp. 351-357, Nice, France.

[41] Nilsson K (2012) Patent Application SE-1251196-0: Method and System for Determination of at least one Property of a Manipulator.

[42] Wang Z, Mastrogiacomo L, Franceschini F, Maropoulos P (2011) Experimental comparison of dynamic tracking performance of iGPS and laser tracker. In: International Journal of Advanced Manufacturing Technology 56 (1-4): 205-213.

[43] Schneider U, Diaz Posada JR, Drust M, Verl A (2013) Position control of an industrial robot using an optical measurement system for machining purposes. In: International Conference on Manufacturing Research (ICMR), pp. 307-312, Cranfield University, United Kingdom.

[44] Schneider U, Oloffson B, Sörnmo O, Drust M, Robertsson A, Hägele M, Johansson R (2013) Integrated Approach to Robotic Machining with Macro/Micro Actuation. In: International Journal of Robotics and Computer-Integrated Manufacturing, submitted. 
[45]Puzik A, Meyer C, Verl A (2010) Industrial Robots for Machining Processes in Combination with a 3D-Piezo-Compensation-Mechanism. In: $7^{\text {th }}$ CIRP International Conference on Intelligent Computation in Manufacturing Engineering (ICME), Capri, Italy.

[46] Schneider U, Drust M, Puzik A, Verl A (2013) Compensation of Errors in Robot Machining With a Parallel 3D-Piezo Compensation Mechanism. In: 46 ${ }^{\text {th }}$ CIRP Conference on Manufacturing Systems, pp. 305-310, Sesimbra, Portugal.

[47] Olofsson B, Sörnmo O, Schneider U, Robertsson A, Puzik A, Johansson R (2011) Modeling and control of a piezo-actuated high-dynamic compensation mechanism for industrial robots. In: IEEE/RSJ International Conference on Intelligent Robots and Systems (IROS), pp. 4704-4709.

[48] Sörnmo O, Olofsson B, Schneider U, Robertsson A, Johansson R (2012) Increasing the milling accuracy for industrial robots using a piezo-actuated high-dynamic micro manipulator. In: IEEE/ASME International Conference on Advanced Intelligent Mechatronics (AIM), pp.104-110, Kaohsiung, Taiwan. 